\title{
Identification and Characterization of Chromosome Regions Associated With Salinity Tolerance in Rice
}

\author{
Nguyen Thi Thu Thuy ${ }^{1}$, Misato Tokuyasu ${ }^{2}$, Nguyen Sao Mai ${ }^{1} \&$ Yoshihiko Hirai ${ }^{1}$ \\ ${ }^{1}$ Graduate School of Environmental and Life Science, Okayama University, Okayama, Japan \\ ${ }^{2}$ Faculty of Agriculture, Okayama University, Okayama, Japan \\ Correspondence: Yoshihiko Hirai, Graduate School of Environmental and Life Science, Okayama University, \\ Okayama, Japan. Tel: 81-86-251-8316. E-mail: yhirai@okayama-u.ac.jp
}

\author{
Received: July 16, $2018 \quad$ Accepted: August 16, $2018 \quad$ Online Published: October 15, 2018 \\ doi:10.5539/jas.v10n11p57 URL: https://doi.org/10.5539/jas.v10n11p57
}

\begin{abstract}
Rice, the major crop sustaining approximately half the world population, has been extensively reported to be sensitive to saline conditions. However, the genetic and physiological understanding related to long-term salinity stress remains unclear so far. The aim of this study was to evaluate the mechanisms of salinity tolerance in a salinity-tolerant variety of rice, Nona Bokra, and to detect the chromosomal regions responsible for it. We utilized chromosome segment substitution lines (CSSLs) carrying segments from Nona Bokra in the genetic background of a salt-sensitive variety Koshihikari by investigating the plant growth, grain productivity, and ion contents in plants subjected to long-term salinity stress. Comparison of plant growth and grain yield of CSSLs grown under long-term saline conditions suggests that the salinity tolerance of Nona Bokra involves the improvement of plant dry matter, panicle number, and percentage of ripened grains. Nona Bokra has the chromosomal regions for the improvement of the panicle number on chromosome 2 and the percentage of ripened grains on chromosome 6 or 10 under salinity conditions. It was suggested that these chromosomal regions were related to $\mathrm{Na}^{+}$and $\mathrm{Cl}^{-}$exclusion. Low $\mathrm{Na}^{+}$and $\mathrm{Cl}^{-}$contents in whole plant at full heading stage would be vital for improving the yield under long-term saline conditions.
\end{abstract}

Keywords: chromosome segment substitution lines, Nona Bokra, rice, salinity tolerance

\section{Introduction}

Rice is one of the principal crops in the world, and it is the single most important source of employment and income in rural Asia (Hoang et al., 2016; Khan et al., 2016). The world population is projected to reach 9.1 billion by 2050 , and this necessitates an increase in food production by about $70 \%$ in order to sustain this large population (Food and Agriculture Organization, 2009; Godfray et al., 2010). Therefore, it is important to increase rice productivity to meet the demand. It is reported that over 800 million ha (mha) of farmland is affected by salinity globally (Hoang et al., 2016), and each year an area of approximately 10 mha of irrigated land is abandoned due to salinity (Pessarakli \& Szabolcs, 1999). Rice is one of the most salt-sensitive crops (Munns \& Tester, 2008). The threshold ECe for rice is $3 \mathrm{dS} \mathrm{m}^{-1}$ with $12 \%$ reduction in yield per unit rise of ECe beyond this threshold (Maas \& Hoffman, 1977). Loss of rice yield due to salinity stress is estimated to be between $10 \%$ to $80 \%$, and when this is coupled with erratic rainfall, it can reach up to $100 \%$ (Vinod et al., 2013). Hence, it is essential to enhance the salinity tolerance of rice in order to enable adequate food production for the rice-consuming populations.

Salinity tolerance of rice can be classified into three main mechanisms: ion exclusion, osmotic tolerance, and tissue tolerance (Munns \& Tester, 2008). The mechanism of $\mathrm{Na}^{+}$exclusion is the ability to avoid toxic concentration within leaves for the long term, and osmotic tolerance and tissue tolerance are the abilities to maintain growth for a given accumulation of $\mathrm{Na}^{+}$in the leaf tissue. Varietal difference in salinity tolerance in rice is closely related to differences of $\mathrm{Na}^{+}$accumulation in the shoot, owing to a negative correlation between sodium content in plant and salinity tolerance traits such as survival (Flowers \& Yeo, 1981; Yeo \& Flowers, 1983), chlorophyll content (Yeo \& Flowers, 1983), photosynthesis (Maegawa et al., 1987; Yeo et al., 1985), and plant growth (Akita \& Cabuslay, 1990). Thus, most research on salinity tolerance in rice focuses on the toxicity of $\mathrm{Na}^{+}$. Furthermore, the salinity tolerance in rice is known to differ during the growing stage (Heenan et al., 1988; Makihara et al., 1999a; Makihara et al., 1999b), and its tolerance at different stages seems to be controlled 
by independent genes (Singh et al., 2010). However, it is unclear at which growth stage $\mathrm{Na}^{+}$exclusion mechanism is essential to enhance salinity tolerance relating grain productivity.

Salinity tolerance is generally considered as a complex quantitative trait controlled by multiple genes involved in several physiological mechanisms (Flowers, 2004). This makes the attempts at breeding to improve the salinity tolerance more difficult. It is necessary to know which mechanism is important to improve the grain productivity under salinity stress and to know its chromosomal region. Chromosome segment substitution lines (CSSLs) are useful plant materials to simplify the genetic background (Ebitani et al., 2005; Yano, 2001), since they usually carry one distinct chromosome segment from a donor parent in the chromosome background of a recurrent parent. CSSLs are useful for the detection of quantitative trait loci (QTL) and for narrowing the QTL region to identify the responsible gene (Ebitani et al., 2005; Yano, 2001). However, there have not been many reports on QTL mapping for salinity tolerance using rice CSSLs. Nona Bokra is one of the most salt-tolerant varieties of rice (Yeo et al., 1990). Using Nona Bokra, several QTLs related to salt tolerance at a vegetative stage, such as SKC1, qSNC-7, and other minor QTLs have been reported (Lin et al., 2004; Puram et al., 2017; Ren et al., 2005). The QTLs accountable for salinity tolerance at the seedling and reproductive stages are different (Hossain et al., 2014), however, there have not been reported on QTL mapping for salinity tolerance-related grain productivity using Nona Bokra.

In this work, to evaluate the tolerance mechanisms relating grain productivity in a salinity resistance variety, Nona Bokra, and to detect the chromosomal regions responsible for it, we screened for CSSLs carrying segments from Nona Bokra in the genetic background of a salt-sensitive variety Koshihikari by investigating the plant growth, grain productivity, and the shoot ion contents under long-term salinity stress conditions of the selected lines at different growth stage under long-term salinity conditions.

\section{Materials and Methods}

\subsection{Plant Materials and Growth Conditions}

\subsubsection{Experiment 1: Comparison of Salinity Tolerance in CSSLs}

A set of 44 CSSLs, developed from salt-sensitive japonica variety Koshihikari (the recipient) and salt-tolerant indica variety Nona Bokra (the donor) (Takai et al., 2007), and parent variety Koshihikari were used in this study. Seeds were obtained from the Rice Genome Resource Center in Japan.

The experiments were carried out in a vinyl house in the experimental field of Okayama University. Pre-germinated seeds were seeded on May 23, 2014, in nursery boxes (Minoru pot 448, Minoru Industrial Co. Ltd., Japan) with 448 holes (16 mm diameter, $25 \mathrm{~mm}$ depth). One seed was seeded in each hole. All the holes were filled with nursery soil for rice seedlings (Kumiai Ube Ryu-joh Baido, Ube Industries Ltd., Japan). The nursery boxes were placed in the field mixed with compound fertilizer (NPK 16-16-16) at a dosage of $180 \mathrm{~g} \mathrm{~m}^{-2}$, on May 27, 2014. Three seedlings in each line were individually transplanted into $2 \mathrm{~L}$ pots filled with paddy soil on June 13. Slow-release compound (NPK 14-14-14) fertilizer was mixed with soil (7 g per pot). The pots were kept flooded in a large tank $(20 \mathrm{~m} \times 1.1 \mathrm{~m} \times 0.18 \mathrm{~m})$ inside the vinyl house. Water was supplied through an irrigation tube (Evaflow, Mitsui Chemicals Inc.). $\mathrm{NaCl}$ was applied to the tank on day 7 and day 10 after transplantation to induce salinity stress, and the electrical conductivity (EC) in the solutions was maintained at approximately $7.5 \mathrm{dS} \mathrm{m}^{-1}$ (aproximately $65 \mathrm{mM} \mathrm{NaCl}$ ) during the growth duration. The plants planted in the tank without $\mathrm{NaCl}$ were used as controls.

Pots were arranged in a randomized complete block design, with three replications for each line. Short-day treatment (day/night: $10 \mathrm{~h} / 14 \mathrm{~h}$ ) by using a shading sheet was conducted for several CSSLs, including SL508, SL509, SL510, SL519, SL520, SL521, SL523, SL526, and SL537 from July 10 to July 24. The heading date of each plant was recorded. At maturity stage, three plants in each line were uprooted and subsequently separated into leaf plus stem and panicle. Leaf plus stem were oven-dried at $80{ }^{\circ} \mathrm{C}$ for three days, following which the dry weight was measured. The ripened spikelet was separated by sinking in salt water with a specific gravity of 1.06 . The grain weight was then measured after oven-drying at $80^{\circ} \mathrm{C}$ for three days.

\subsubsection{Experiment 2: Charactarization of Chromosomal Regions Related to Salinity Tolerance}

The procedure for this experiment was similar to that of Experiment 1. Four CSSLs (SL506, SL516, SL535, and SL540) selected based on high grain yield, two CSSLs (SL502 and SL528) selected based on high grain yield (not significant) with high plant dry weight in experiment 1, and Koshihikari were used. Pre-germinated seeds were seeded on May 19, 2015 in nursery boxes. Thirteen seedlings in each line were individually transplanted into $2 \mathrm{~L}$ pots on June 9 . $\mathrm{NaCl}$ was applied to the tank at day 7 and day 13 after transplantation, and the $\mathrm{EC}$ of the tank was maintained at approximately $7.5 \mathrm{dS} \mathrm{m}^{-1}$ during the growth duration. Four plants in each line were 
uprooted at day 29 after the salt treatment (29DAT) and at full heading stage, and five plants were uprooted at maturity stage for the determination of plant dry weight, yield, yield components and ion content. The following yield components were investigated: panicle number per plant, spikelet number per panicle, percentage of ripened grains, and 1000-grain weight. The percentage of ripened grains was determined as the percentage of ripened spikelet relative to the total number of spikelets per panicle.

\subsection{Ion Content}

The ion content of the plants was measured at 29 DAT, full heading, and maturity stages using four replications in each line. Approximately $0.5 \mathrm{~g}$ shoot sample was chopped and placed in a tube before being vigorously mixed with $25 \mathrm{~mL}$ of $1 \%$ nitric acid. This mixture was stored in an oven at $80{ }^{\circ} \mathrm{C}$ for 24 hours to extract the ions. $\mathrm{Na}^{+}$ and $\mathrm{K}^{+}$contents of the extracted solution were determined by a Flame photometer (BWB-XP, BWB Technologies, UK), and $\mathrm{Cl}^{-}$content was determined by a pH/ion meter (D-53, Horiba Ltd., Japan).

\subsection{Statistical Analysis}

Significant differences in dry weight, yield components, and ion contents between Koshihikari and each CSSLs were determined by Dunnett's test (JMP software version 9.0). The correlations between character pairs were computed at $\mathrm{P}<0.05$ and $\mathrm{P}<0.01$ in Microsoft Excel using trait averages.

\section{Results}

\subsection{Identification of CSSLs Exhibiting Salinity Tolerance Traits at Maturity Stage}

Plant dry weight at maturity stage of the CSSLs and their parent Koshihikari was determined after cultivation under either saline or control conditions (Figure 1). Under control conditions, only two CSSLs (SL516 and SL518) showed significantly higher plant dry weight compared to that of Koshihikari (Figure 1a). Under saline conditions, the plant dry weight of all lines was greatly reduced compared to the control conditions. However, ten CSSLs (SL502, SL508, SL511, SL516, SL520, SL527, SL528, SL529, SL535, and SL540) exhibited higher plant dry weight in comparison to that of Koshihikari (Figure 1b).

The grain yields of the CSSLs and Koshihikari under saline and control conditions are shown in Figure 2. Under control conditions, the grain yield in SL516 and SL518 is higher than that in Koshihikari (Figure 2a). However, when grown under saline conditions, the grain yield in SL516 remained higher compared to Koshihikari while that in SL518 did not (Figure 2b). The grain yield in SL528 was significantly lower than in Koshihikari under control conditions, as opposed to being substantially higher under saline conditions. The grain yield in SL506, SL535, and SL540 did not significantly differ from that of Koshihikari under control conditions, but it was higher than the yield of Koshihikari under saline conditions. 

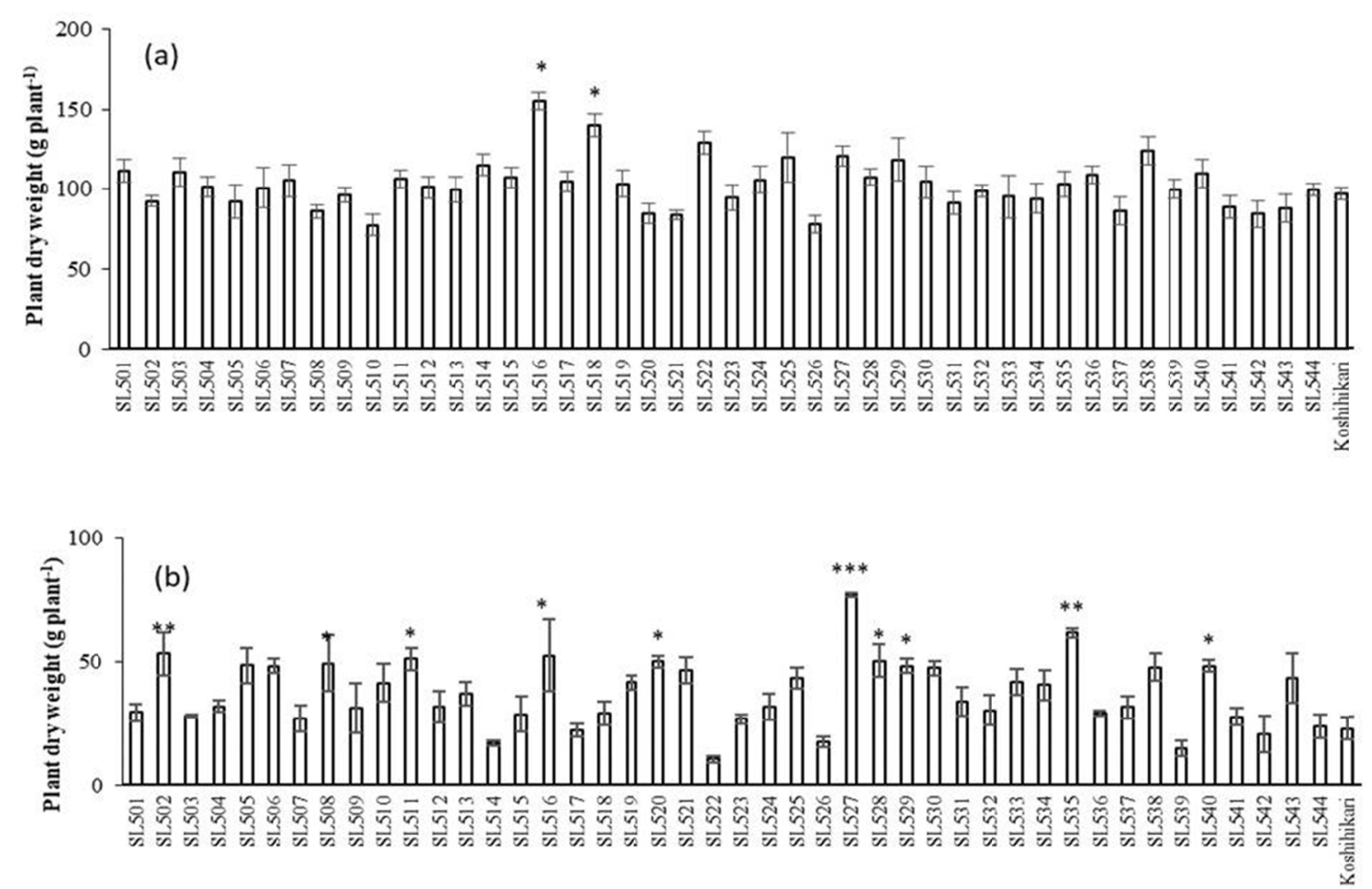

Figure 1. Plant dry weight of the CSSLs and Koshihikari under control (a) and saline (b) conditions. Bars show the average value $\pm \operatorname{SE}(n=3)$ plant dry weight of CSSLs compared with that of Koshihikari by Dunnet's multiple t-test. The $*,{ }^{* *}$, and $* * *$ indicate significance at $\mathrm{p}<0.05, \mathrm{p}<0.01$, and $\mathrm{p}<0.001$ respectively
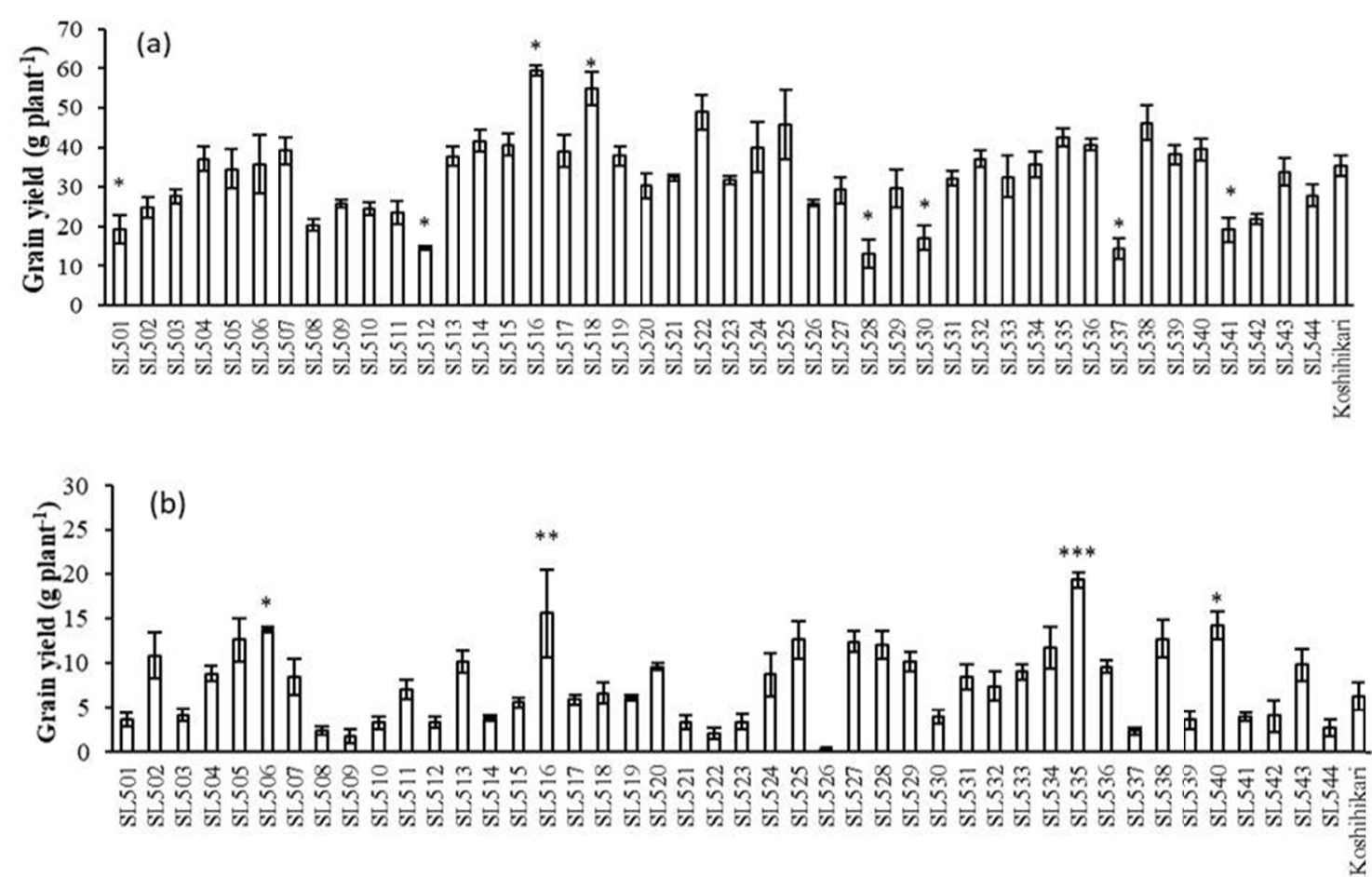

Figure 2. Grain yield of CSSLs population and Koshihikari under control (a) and saline (b) conditions. Bars show the average value $\pm \mathrm{SE}(\mathrm{n}=3)$ grain yield of CSSLs compared with that of Koshihikari by Dunnet's multiple t-test. *, **, and $* * *$ indicate significance at $\mathrm{p}<0.05, \mathrm{p}<0.01, \mathrm{p}<0.001$, respectively 


\subsection{Differences in Plant Dry Weight of the Selected CSSLs Among Different Growth Stages}

Figure 3 shows the plant dry weight of the selected CSSLs and Koshihikari during different growth stages under saline and control conditions. At 29 DAT, under saline conditions, plant dry weight in the two CSSLs (SL528 and SL535) exhibited significantly higher than that of Koshihikari, but the plant dry weights in all the CSSLs did not statistically differ from that of Koshihikari under control conditions (Figure 3a). At full heading stage, five CSSLs (SL502, SL506, SL528, SL535, and SL540) exhibited significantly higher than that of Koshihikari under saline conditions (Figure 3b). SL528 additionally showed higher plant dry weight compared to Koshihikari when grown under control conditions. Three CSSLs (SL506, SL528, and SL535) showed significantly higher plant dry weights at maturity stage as compared to that of Koshihikari under saline conditions. However, under control conditions, plant dry weights in the six CSSLs did not significantly differ from Koshihikari (Figure 3c). Overall, the selected CSSLs exhibited different responses in salt tolerance related to plant dry weight among growth stages. SL528 and SL535 consistently exhibited salinity tolerance traits throughout the growth stages.
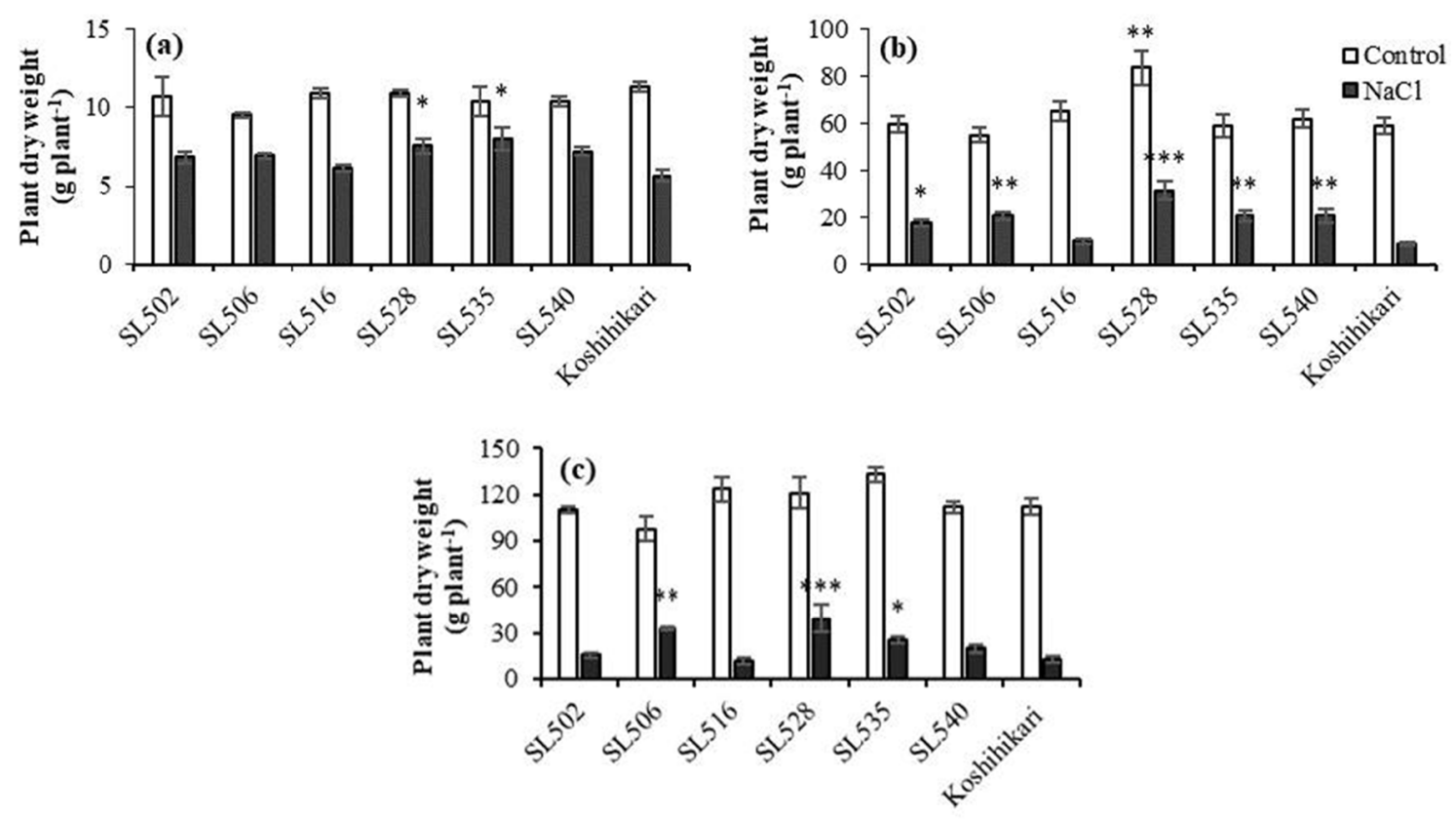

Figure 3. Plant dry weight of selected CSSLs and Koshihikari at: (a) 29 DAT, (b) full heading stage, and (c) maturity stage. Bars show the average value $\pm \operatorname{SE}(n=4$ at $29 \mathrm{DAT}$ and full heading stage; $\mathrm{n}=5$ at maturity stage) plant dry weight of CSSLs compared with that of Koshihikari by Dunnet's multiple t-test. *, **, and *** indicate significance at $\mathrm{p}<0.05, \mathrm{p}<0.01$, and $\mathrm{p}<0.001$, respectively

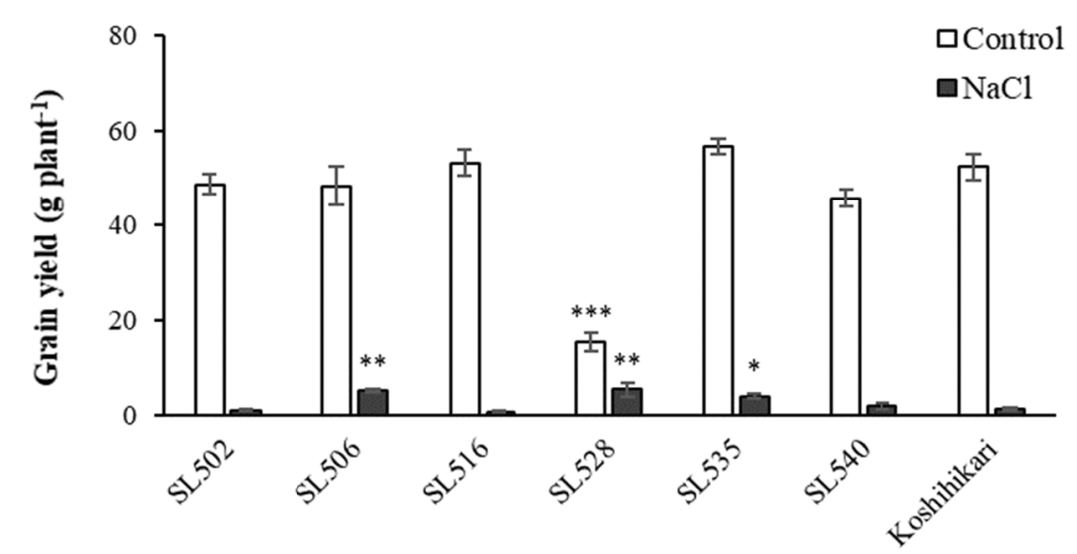

Figure 4. Grain yield of selected CSSLs and Koshihikari. Bars show the average value $\pm \operatorname{SE}(n=5)$ plant dry weight of CSSLs compared with that of Koshihikari by Dunnet's multiple t-test. ${ }^{*}, * *$, and $* * *$ indicate significance at $\mathrm{p}<0.05$, $\mathrm{p}<0.01$, and $\mathrm{p}<0.001$, respectively 


\subsection{Grain Yields and Yield Components of the Selected CSSLs Under Salinity Stress}

As depicted in Figure 4, the grain yields of all the CSSLs, except for SL528, under control conditionvs were not significantly different fom that of Koshihikari. However, under saline conditions, SL506, SL528, and SL535 showed higher grain yields as compared to Koshihikari. There was no difference in the number of panicles between all the CSSLs and Koshihikari under control conditions, while SL506 and SL528 showed significantly high number of panicles under saline conditions (Figure 5a). As for the number of grains per panicle, SL516 and SL528 showed significantly high numbers under control conditions, whereas no significant differences were observed under saline conditions (Figure 5b). No significant differences were found in 1000-grain weight among the CSSLs and Koshihikari under saline conditions (Figure 5c). The percentage of ripened grains of the CSSLs was not significantly higher than that of Koshihikari under control conditions. Nevertheless, SL535 showed a higher percentage under saline conditions as compared to Koshihikari (Figure 5d).
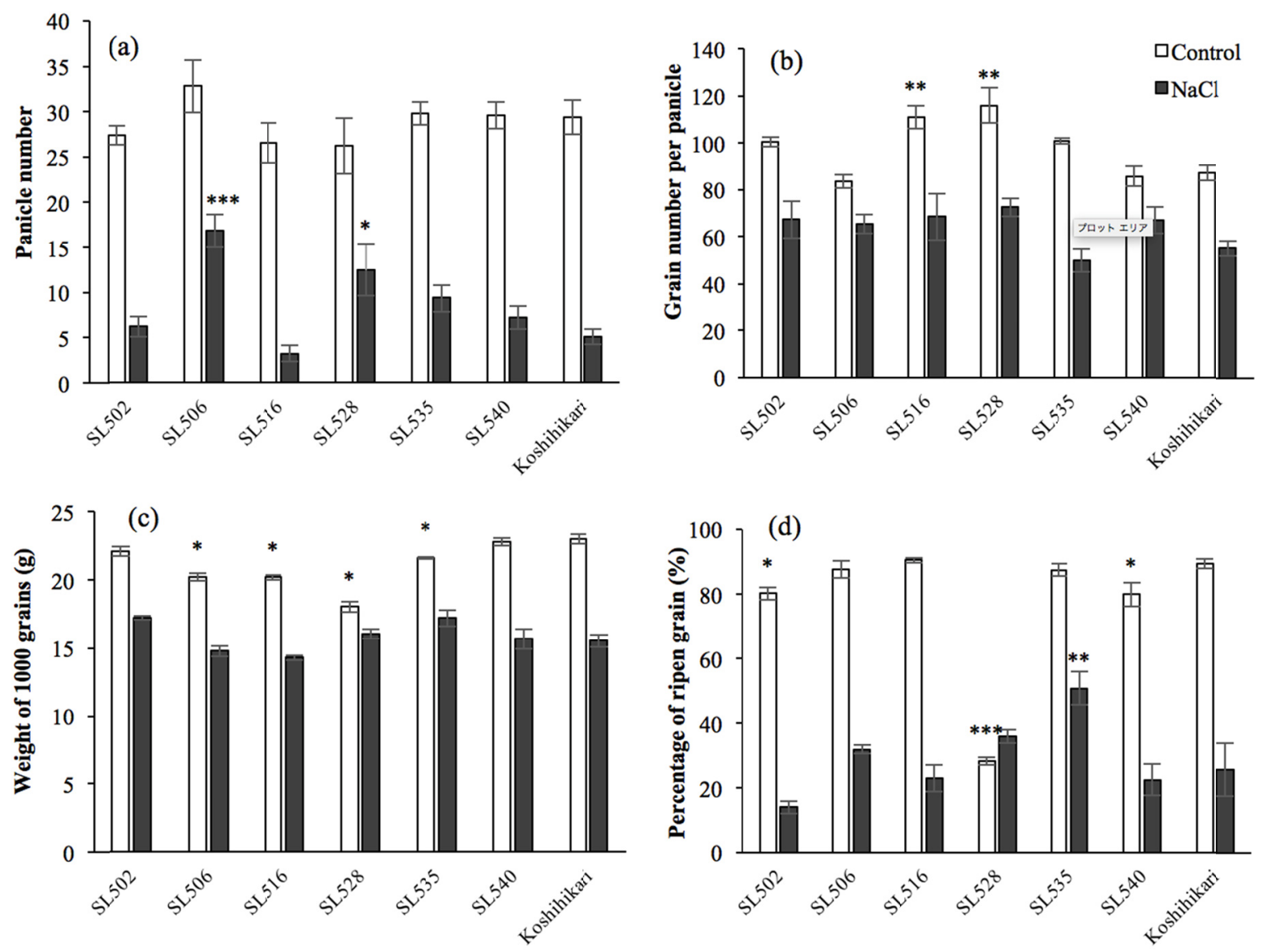

Figure 5. Yield components of selected CSSLs and Koshihikari: (a) Panicle number per plant; (b) Grain number per panicle; (c) Weight of 1000 grains, and (d) Percentage of ripened grain. Bars show the average value $\pm \operatorname{SE}(n=5)$ each yield component of CSSLs compared with that of Koshihikari by Dunnet's multiple t-test. *, ** and *** indicate significance at $\mathrm{p}<0.05, \mathrm{p}<0.01$, and $\mathrm{p}<0.001$, respectively

\subsection{Ion Content of CSSLs Grown Under Saline Conditions}

$\mathrm{Na}^{+}$contents of the whole plant in CSSLs and Koshihikari under saline conditions were higher than those under control conditions at three different growth stages (Figure 6). $\mathrm{Na}^{+}$contents of the whole plant in SL535 and SL540 at 29 DAT, in SL528 at full heading stage, and in SL506 at maturity stage were lower than those in Koshihikari under saline conditions. There was no difference in the $\mathrm{Cl}^{-}$content of the whole plant at 29DAT, however, in SL528 at full heading stage, and in SL506 at maturity stage, it was lower than that in Koshihikari under saline conditions. 

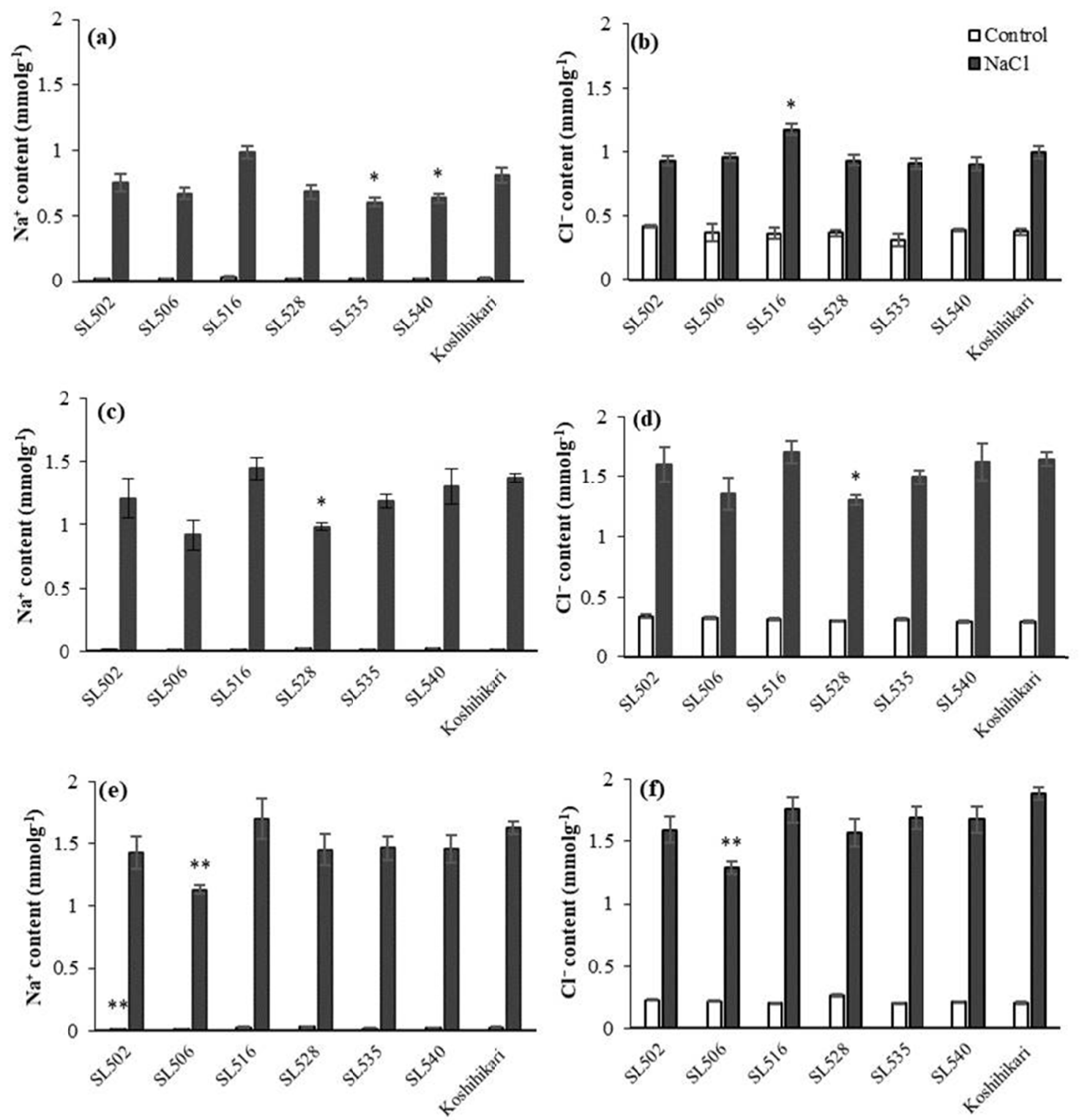

Figure. 6. The ion content in the whole plant at 29 DAT: (a) $\mathrm{Na}^{+}$, (b) $\mathrm{Cl}^{-}$; At heading stage: (c) $\mathrm{Na}^{+}$, (d) $\mathrm{Cl}^{-}$; At maturity stage: (e) $\mathrm{Na}^{+},(\mathrm{g}) \mathrm{Cl}^{-}$. Values indicate means $\pm \mathrm{SE}(\mathrm{n}=4$ at 29DAT and full heading stage; $\mathrm{n}=5$ at maturity stage). Significant differences of each variety from Koshihikari were evaluated by Dunnet's multiple t-test. ${ }^{*}, *$, and $* * *$ indicate significance at $\mathrm{p}<0.05, \mathrm{p}<0.01$, and $\mathrm{p}<0.001$, respectively

\subsection{Correlation Between Ion Content at Different Growth Stages and Plant Growth Traits in CSSL Under Salinity Stress}

Table 1 showed the correlations between the ion content of the whole plant and plant dry weight at different growth stages, as well as grain yield and yield components for the selected CSSLs under saline conditions. The $\mathrm{Cl}^{-}$content of the whole plant at full heading stage strongly correlated with plant dry weight at maturity stage, grain yield, and the number of panicles as $\mathrm{R}^{2}=0.961,0.936$, and 0.859 respectively (Figure 7). Equally, the $\mathrm{Na}^{+}$ content of the whole plant at full heading stage strongly correlated with plant dry weight at maturity stage, grain yield, and panicle number, indicated by $\mathrm{R}^{2}=0.841,0.821$, and 0.923 , respectively. Overall, ion content of the whole plant at full heading stage was shown to have the highest corelation with plant dry weight at maturity stage, panicle number, and grain yield. 

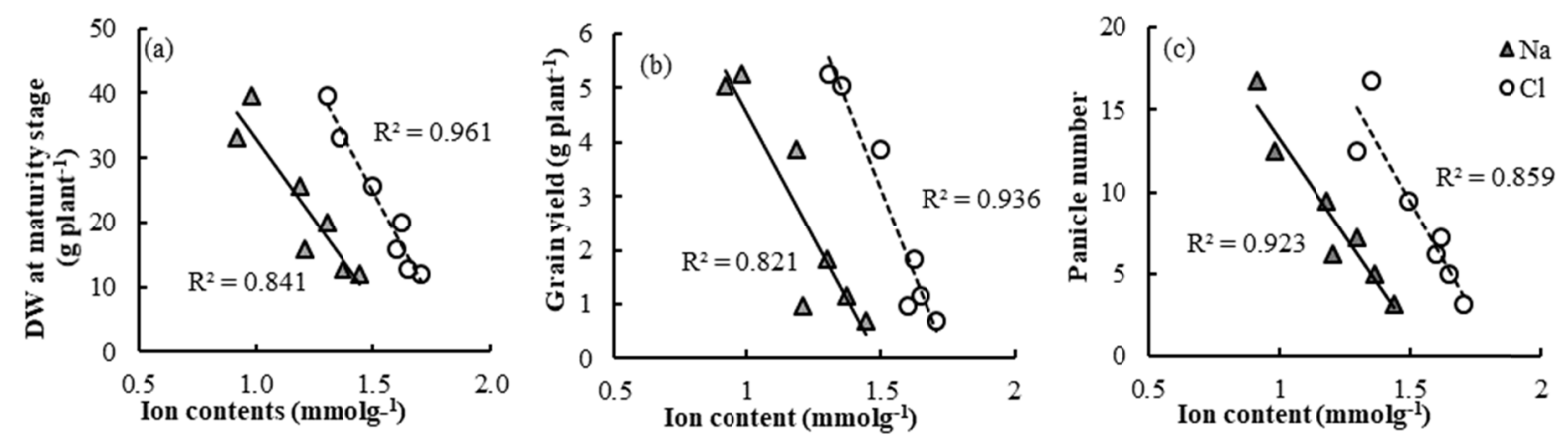

Figure 7. The correlation between ion content at full heading stage and (a) plant dry weight; (b) grain yield, and (c) number of panicles per plant. Plant samples were taken from selected CSSLs and Koshihikari under saline conditions

Table 1. Correlation coefficient (r) between ion contents and plant dry weight, yield, and yield components under saline conditions

\begin{tabular}{lllllllll}
\hline \multirow{2}{*}{ Ion content } & $\begin{array}{l}\text { PDW at } \\
\text { 29 DAT }\end{array}$ & $\begin{array}{l}\text { PDW at } \\
\text { FHS }\end{array}$ & $\begin{array}{l}\text { PDW at } \\
\text { MS }\end{array}$ & \multirow{2}{*}{ Grain yield } & \multirow{2}{*}{ Panicle no } & $\begin{array}{l}\text { GN/ } \\
\text { panicle }\end{array}$ & $\begin{array}{l}1000 \\
\text { GW }\end{array}$ & \multirow{2}{*}{$\%$ of RG } \\
\hline $\mathrm{Na}^{+}$at 29DAT & $-0.777^{*}$ & $-0.702^{*}$ & $-0.634^{*}$ & -0.644 & -0.640 & 0.239 & -0.5563 & -0.506 \\
$\mathrm{Cl}^{-}$at 29DAT & -0.658 & -0.641 & -0.500 & -0.470 & -0.488 & 0.195 & $-0.709^{*}$ & -0.291 \\
$\mathrm{Na}^{+}$at FHS & -0.574 & $-0.781^{*}$ & $-0.917^{* *}$ & $-0.906^{* *}$ & $-0.961^{* *}$ & -0.224 & -0.154 & -0.393 \\
$\mathrm{Cl}^{-}$at FHS & -0.610 & $-0.837^{* *}$ & $-0.980^{* *}$ & $-0.967^{* *}$ & $-0.927^{* *}$ & -0.198 & -0.131 & -0.537 \\
$\mathrm{Na}^{+}$at MS & -0.465 & -0.541 & -0.664 & $-0.689^{*}$ & $-0.895^{* *}$ & -0.126 & -0.090 & -0.190 \\
$\mathrm{Cl}^{-}$at MS & -0.442 & -0.567 & $-0.695^{*}$ & $-0.684^{*}$ & $-0.868^{* *}$ & -0.385 & 0.077 & -0.117 \\
\hline
\end{tabular}

Note. DAT $=$ Day after treatment; FHS $=$ Full heading stage $;$ MS = Maturity stage; PDW = Plant dry weight; RG $=$ Ripen grain; $\mathrm{GW}=$ Gain weight $; \mathrm{GN}=$ Grain number.

Data was analyzed using JMP software (version 9.0.0), and the correlations between character pairs were computed at $\mathrm{p}<0.05$ and $\mathrm{p}<0.01$. NS. The $*$ and $* *$ indicate non-significance or significance at $\mathrm{p}<0.05$ and $\mathrm{p}<0.01$, respectively.

\section{Discussion}

Nona Bokra is a well-known salinity-tolerant donor in conventional rice breeding. In this study, we characterized the responses of 44 CSSLs carrying segments from Nona Bokra in the genetic background of Koshihikari under long-term salinity conditions. The results showed: (i) several CSSLs performed salinity tolerance for higher plant dry weight (Figure 3), grain yield (Figure 4), and yield components (Figuare 5) than those of Koshihikari; (ii) the timing of low $\mathrm{Na}^{+}$or $\mathrm{Cl}^{-}$contents in whole plant under saline conditions was different among the CSSLs (Figure 6); and, (iii) $\mathrm{Na}^{+}$and $\mathrm{Cl}^{-}$contents of plants at full heading stage were highly correlated with grain yield and panicle number (Figure7).

\subsection{Nona Bokra Segments Improved Plant Dry Weight and Grain Yield in CSSLs Under Long-Term Salt Stress}

The salinity tolerance for the growth and grain yield of six CSSLs selected from the results in 2014 was compared with that of Koshihikari at different growth stages under saline conditions in 2015, then, five CSSLs, exept for SL516, showed salinity tolerance, showed higher plant dry weight at least in one of the growth stages or in higher grain yield compared to Koshihikari under saline conditions (Figures 3 and 4). Since these lines differ in chromosome substitution regions derived from Nona Bokra (Takai et al., 2007), the results suggest that Nona Bokra contains multiple chromosomal regions related to salinity tolerance. The salinity tolerance in rice is known to differ according to the growth stage (Aslam, Qureshi, \& Ahmad, 1993; Heenan et al., 1988; Lutts, Kinet, \& Bouharmont, 1995; Makihara et al., 1999a; Makihara et al., 1999b). In this study, SL502 and SL540 exhibited higher salinity tolerance in plant dry weight than Koshihikari only at full heading stage (Figure 3b), while SL528 and SL535 showed higher salinity tolerance than Koshihikari from 29 DAT to maturity stage (Figure 3). The difference in timing expressed by salinity tolerance in these CSSLs is considered to involve different genes of salinity tolerance of Nona Bokra.

Salinity stress reduces grain yield and yield components such as the number of panicles, the number of grains per panicle, the percentage of ripened grains, and 1000-grain weight (Heenan et al., 1988; Khatun, Rizzo, \& Flowers, 1995; 
Makihara et al., 1999a; Makihara et al., 1999b; Zeng \& Shannon, 2000). In this study, the grain yield and yield components of the selected CSSLs, in addition to Koshihikari, were greatly reduced under saline conditions (Figure 4). Three CSSLs (SL506, SL528, and SL535) depicted a significantly higher yield under saline conditions in comparision to Koshihikari. However, in SL528, semi-sterility was exhibited under control conditions (Figure 4). In our results, the variation among the three CSSLs in terms of the yield components under salinity stress was observed. SL506 with Nona Bokra chromosomal segment on chromosome 2 had higher panicle number under salinity stress compared to Koshihikari (Figure 5a), which suggested that Nona Bokra has the region for improvement of panicle number under salinity stress on chromosome 2. Moreover, SL528 had higher panicle number under salinity stress than Koshihikari, while lower spikelet fertility was accompanied (Figures 5a and 5d). Most of the Nona Bokra chromosome segments in SL528 are derived from chromosome 8, but a few segments were derived from chromosomes 1, 2, 5, and 6 as well (Takai et al., 2007). Since SL528 and SL506 contain the same chromosomal region on chromosome 2, and they exhibited similar salinity tolerance, the higher panicle number in both CSSLs under saline conditions may be related to the same chromosomal region on chromosome 2. SL535 with Nona Bokra chromosomal segment on chromosome 6 and 10 had higher percentage of ripened grains than Koshihikari (Figure 5d), suggesting that Nona Bokra has the region for improvement of percentage of ripened grains under salinity conditions on chromosome 6 or 10 .

While SL502 and SL540 showed salinity tolerance with respect to high plant dry weight at full heading stage (Figure $3 b)$, their plant dry weights at maturity stage and the grain yield as well as yield components under saline conditions were not significantly different from Koshihikari (Figures 3c, 4, and 5). This indicates that the Nona Bokra segments contained in SL502 and SL540 are responsible for the saline tolerance until the full heading stage. SL502 harbor the chromosome segment containing Nona Bokra SKC1 on chromosome 1. SKC1 encodes HKT1;5, a selective transporter for $\mathrm{Na}^{+}$, regulating $\mathrm{K}^{+} / \mathrm{Na}^{+}$homeostasis and conferring salinity tolerance (Ren et al., 2005). The salinity tolerance of SKC1 gene was evaluated at the seedling stage (Lin et al., 2004; Ren et al., 2005). These evidences suggest that $\mathrm{SKC1}$ gene under saline conditions relates to salinity tolerance until full heading stage.

\subsection{Ion Exclusion Affects Grain Yield and Yield Components}

Ion exclusion is unquestionably one of the most studied salinity tolerance mechanism, owing to the simplicity in its phenotyping (Pires, Negrão, Oliveira, \& Purugganan, 2015; Roy, Negrão, \& Tester, 2014). In this study, a negative correlation between sodium content in plants and plant dry weight at 29DAT or at full heading stage was observed (Table 1), in addition, a negative correlation between chloride content in plants and plant dry weight at full heading stage or maturity stage. Additionally, the timing of low $\mathrm{Na}^{+}$or $\mathrm{Cl}^{-}$contents in whole plant under saline conditions was different among the CSSLs (SL506, SL 528, SL535, and SL540) (Figure 6). The results suggest that Nona Bokra has multiple chromosomal regions related to ion exclusion. The sensitivity to salinity stress differs depending on the growth stage, with the early seedling and reproductive stages considered the most sensitive (Makihara et al., 1999a; Singh et al., 2010). The results in the correlations between ion content of plant in different growth stages and grain yield under salinity stress show that $\mathrm{Na}^{+}$and $\mathrm{Cl}^{-}$contents of plants at full heading stage were highly correlated with grain yield and panicle number (Figure 7 and Table 1). It suggests that low $\mathrm{Na}^{+}$and $\mathrm{Cl}^{-}$contents in whole plant at full heading stage is more important for salinity tolerance relating grain productivity than that at vegetative stage. There have been several reports on QTLs for shoot $\mathrm{Na}^{+}$content (Gautam, Singh, \& Qadar, 2009; Negrao et al., 2011) and for grain yield (Bimpong et al., 2014; Hossain et al., 2015; Mohammadi, Mendioro, Diaz, Gregorio \& Singh, 2013), however it has not been reported that these QTLs are in the same chromosomal region. In this study, it was suggested that $\mathrm{Na}^{+}$and $\mathrm{Cl}^{-}$contents in whole plant were related to several chromosomal regions, and chromosomal regions controlling $\mathrm{Na}^{+}$and $\mathrm{Cl}^{-}$contents at full heading stage was important for improving the grain productivity under saline conditions. Analysis of the QTL controlling $\mathrm{Na}^{+}$and $\mathrm{Cl}^{-}$contents in plant at full heading stage will be the subject of further study.

\section{Conclusion}

The comparison of plant growth and grain yield of CSSLs grown under long-term saline conditions suggests that the salinity tolerance of Nona Bokra involves the improvement of plant dry matter, panicle number, and percentage of ripened grains. Nona Bokra has the chromosomal regions for the improvement of the panicle number on chromosome 2 and the percentage of ripened grains on chromosome 6 or 10 under salinity conditions. It was suggested that these chromosomal regions were related to $\mathrm{Na}^{+}$and $\mathrm{Cl}^{-}$exclusion. Low $\mathrm{Na}^{+}$and $\mathrm{Cl}^{-}$contents in whole plant at full heading stage would be vital for improving the yield under long-term saline conditions.

\section{References}

Akita, S., \& Cabuslay, G. S. (1990). Physiological basis of differential response to salinity in rice cultivars. Plant and Soil, 123, 277-294. https://doi.org/10.1007/BF00011281 
Aslam, M., Qureshi, R. H., \& Ahmad, N. (1993b). Mechanism of salinity tolerance in rice. Towards the Rational Use of High Salinity Tolerant Plants, 2, 135-138. https://doi.org/10.1007/978-94-011-1860-6_16

Bimpong, I. K., Manneh. B., Diop. B., Ghislain, K., Sow, A., Amoah, N. K. A., ... Wopereis, M. (2014). New quantitative trait loci for enhancing adaptation to salinity in rice from Hasawi, a Saudi landrace into three African cultivars at the reproductive stage. Euphytica, 200, 45-60. https://doi.org/10.1007/s10681-0141134-0

Ebitani, T., Takeuchi, Y., Nonoue, Y., Yamamoto, T., Takeuchi, K., \& Yano, M. (2005). Construction and evaluation of chromosome segment substitution lines carrying overlapping chromosome segments of indica rice cultivar 'Kasalath' in a genetic background of Japonica Elite cultivar 'Koshihikari'. Breeding Science, 55, 65-73. https://doi.org/10.1270/jsbbs.55.65

FAO (Food and Agriculture Organization). (2009). How to Feed the World in 2050. Roma. Retrieved from http://www.fao.org/docrep/012/ak542e/ak542e00.htm

Flowers, T. J. (2004). Improving crop salt tolerance. Journal of Experimental Botany, 55(396), $307-319$. https://doi.org/10.1093/jxb/erh003

Flowers, T. J., \& Yeo, A. R. (1981). Variability in the resistance of sodium chloride salinity within rice (Oryza sativa L.) varieties. New Phytologist, 88, 363-373. https://doi.org/10.1111/j.1469-8137.1981.tb01731.x

Gautam, R. K., Singh, R. K., \& Qadar, A. (2009). Incorporating salt tolerance in rice with more precision-status and prospects. Journal of Soil Salinity \& Water Quality, 1, 73-84.

Godfray, H. C. J., Beddington, J. R., Crute, I. R., Haddad, L., Lawrence, D., Muir, J. F., ... Toulmin, C. (2010). Food Security: The Challenge of Feeding 9 Billion People. Science, 327(5967), 812. https://doi.org/ 10.1126/science. 1185383

Heenan, D. P., Lewin, L. G., \& McCaffery, D. W. (1988). Salinity tolerance in rice varieties at different growth stages. Australian Journal of Experimental Agriculture, 28, 343-349. https://doi.org/10.1071/EA9880343

Hoang, T. M. L, Tran, T. N., Nguyen, T. K. T., Williams, B., Wurm, P., Bellairs, S., \& Mundree, S. (2016). Improvement of Salinity Stress Tolerance in Rice: Challenges and Opportunities. Agronomy, 6(4), 54. https://doi.org/10.3390/agronomy6040054

Hossain, H., Rahman, M. A., Alam, M. S., \& Singh, R. K. (2015). Mapping of quantitative trait loci associated with reproductive stage salt tolerance in rice. Journal of Agronomy and Crop Science, 201(1), 17-31. https://doi.org/10.1111/jac.12086

Khan, S., Javed, M. A., Jahan, N., \& Mana, F. A. (2016). A Short Review on the Development of Salt Tolerant Cultivars in Rice A Short Review on the Development of Salt Tolerant Cultivars in Rice. International Journal of Public Health Science, 5(August), 201-12.

Khatun, S., Rizzo, C. A., \& Flowers, T. J. (1995). Genotypic variation in the effect of salinity on fertility in rice. Plant and Soil, 173(2), 239-250. https://doi.org/10.1007/BF00011461

Kurotani, K., Yamanaka, K., Toda, Y., Ogawa, D., Tanaka, M., Kozawa, H., .. Takeda, T. H. S. (2015). Stress tolerance profiling of a collection of extant salt-tolerant rice varieties and transgenic plants overexpressing abiotic stress tolerance genes. Plant and Cell Physiology, 56(10), 1867-1876. https://doi.org/10.1093/pcp/ pcv106

Lin, H. X., Zhu, M. Z., Yano, M., Gao, J. P., Liang, Z. W., Su, W. A., ... Chao, D. Y. (2004). QTLs for Na ${ }^{+}$and $\mathrm{K}^{+}$uptake of the shoots and roots controlling rice salt tolerance. Theoretical and Applied Genetics, 108, 253-260. http://doi.org/10.1007/s00122-003-1421-y

Lutts, S., Kinet, J. M., \& Bouharmont, J. (1995). Changes in plant response to $\mathrm{NaCl}$ during development of rice (Oryza sativa L.) varieties differing in salinity resistance. Journal of Experimental Botany, 46(12), 1843-1852. https://doi.org/10.1093/jxb/46.12.1843

Ma, N. L., Lah, W. A. C., Kadir, N. A., Mustaqim, M., Rahmat, Z., Ahmad, A.,.. Ismail, M. R. (2018). Susceptibility and Tolerance of Rice Crop to Salt Threat: Physiological and Metabolic Inspections. PLoS ONE, 13(2), 1-17. https://doi.org/10.1371/journal.pone.0192732

Maas, E. V., \& Homan, G. J. (1977). Crop salt tolerance-current assessment. The Journal of the Irrigation and Drainage Division, 103, 115-134. 
Maegawa, M., Yokohama, Y., \& Aruga, Y. (1987). Critical light condition for young Ecklonia cava and Eisenia bicyclis with reference to photosynthesis. Proceeding of the international Seaweed Symposium, 12, 447-455. https://doi.org/10.1007/978-94-009-4057-4_66

Makihara, D., Tsuda, M., Hirai, Y., \& Kuroda, T. (1999a). Effects of saline irrigation at various reproductive stages on rice yield. Japanese Journal of Crop Science, 68, 487-494. https://doi.org/10.1626/jcs.68.487

Makihara, D., Tsuda, M., Morita, M., Hirai, Y., \& Kuroda, T. (1999b). Effect of salinity on the Growth and Development of Rice (Oryza sativa L.) Varieties. Japanese Journal of Tropical Agriculture, 43(4), 285-294.

Mohammadi, R., Mendioro, M. S., Diaz, G. Q., Gregorio, G. B., \& Singh, R. K. (2013). Mapping quantitative trait loci associated with yield and yield components under reproductive stage salinity stress in rice (Oryza sativa L.). Journal of Genetics, 92, 433-443. https://doi.org/10.1007/s12041-013-0285-4

Munns, R. (2005). Genes and Salt Tolerance. New Phytologist, 167(3), 645-63. https://doi.org/10.1111/j.1469-8137. 2005.01487.x

Munns, R., \& Tester, M. (2008). Mechanisms of Salinity Tolerance. Annu. Rev. Plant Biol, 59, 651-681. https://doi.org/10.1146/annurev.arplant.59.032607.092911

Negrao, S., Courtois, B., Ahmadi, N., Abreu, I., Saibo, N., \& Oliveira, M. M. (2011). Recent Updates on Salinity Stress in Rice: From Physiological to Molecular Responses. Critical Reviews in Plant Sciences, 30, 329-77. https://doi.org/10.1080/07352689.2011.587725

Pessarakli, M., \& Szabolcs, I. (1999). Soil Salinity and Sodicity as Particular Plant/Crop stress factors. Handbook of plant and crop stress (pp. 3-21). https://doi.org/10.1201/9780824746728.pt1

Pires, I. S., Negrão, S., Oliveira, M. M., \& Purugganan, M. D. (2015). Comprehensive phenotypic analysis of rice (Oryza sativa) response to salinity stress. Physiologia Plantarum, 155(1), 43-54. https://doi.org/ $10.1111 / \mathrm{ppl} 12356$

Puram, V. R. R., Ontoy, J., Linscombe, S., \& Subudhi, P. K. (2017). Genetic Dissection of Seedling Stage Salinity Tolerance in Rice Using Introgression Lines of a Salt Tolerant Landrace Nona Bokra. Journal of Heredity, 108(6), 658-670. https://doi.org/10.1093/jhered/esx067

Ren, Z. H., Gao, J. P., Li, L. G., Cai, X. L., Huang, W., Chao, D. Y., ... Lin, H. X. (2005). A rice quantitative trait locus for salt tolerance encodes a sodium transporter. Nature Genetics, 37(10), 1141-1146. https://doi.org/ $10.1038 / \mathrm{ng} 1643$

Roy, S. J., Negrão, S., \& Tester, M. (2014). Salt resistant crop plants. Current Opinion in Biotechnology, 26, 115-124. https://doi.org/10.1016/j.copbio.2013.12.004

Singh, R., \& Flowers, T. (2010). Physiology and molecular biology of the effects of salinity on rice in Handbook of Plant and Crop Stress (pp. 899-939).

Takai, T., Nonoue, Y., Yamamoto, S., Yamanouchi, U., Matsubara, K., Liang, Z. W., ... Yano, M. (2007). Development of Chromosome Segment Substitution Lines Derived from Backcross between Indica Donor Rice Cultivar 'Nona Bokra' and japonica Recipient Cultivar 'Koshihikari.' Breeding Science, 57(3), 257-261. https://doi.org/10.1270/jsbbs.57.257

Vinod, K. K., Krishman, S. G., Babu, N. N., Nagarajan, N., \& Singh, A. K. (2013). Improving Salt Tolerance in Rice: Looking beyond the Conventional. Salt Stress in Plants, 219-260. https://doi.org/10.1007/978-1-4614 $-6108-1 \_10$

Yano, M. (2001). Genetic and molecular dissection of naturally occurring variation. Current Opinion in Plant Biology, 4(2), 130-135. https://doi.org/10.1016/S1369-5266(00)00148-5

Yeo, A. R., \& Flowers, T. J. (1983). Varietal differences in the toxicity or sodium ions in rice leaves. Physiol Plant, 59, 189-195. https://doi.org/10.1111/j.1399-3054.1983.tb00756.x

Yeo, A. R., Caporn, S. J. M., \& Flowers, T. J. (1985). The effect of salinity upon photosynthesis in rice (Oryza sativa L.): Gas exchange by individual leaves in relation to their salt content. Journal of Experimental Botany, 36(169), 1240-1248. https://doi.org/10.1093/jxb/36.8.1240

Yeo, A.R., Yeo, M. E., Flowers, S. A., \& Flowers, T. J. (1990). Screening of rice (Oryza sativa L.) genotypes for physiological characters contributing to salinity resistance, and their relationship to overall performance. Theor Appl Genet, 79(3), 377-384. https://doi.org/10.1007/BF01186082 
Zeng, L., \& Shannon, M. C. (2000). Effects of Salinity on Grain Yield and Yield Components of Rice at different Seeding Densities. Agronomy Journal, 92(3), 418-423. https://doi.org/10.2134/agronj2000.923418x

Zeng, L., \& Shannon, M. C. (2000). Salinity effects on seedling growth and yield components of rice. Crop Sci, 40(4), 996-1003. https://doi.org/10.2135/cropsci2000.404996x

Zeng, L., Shannon, M. C., \& Lesch, S. M. (2001). Timing of salinity stress affects rice growth and yield components. Agricultural Water Management, 48(3), 191-206. https://doi.org/10.1016/S0378-3774(00) 00146-3

\section{Copyrights}

Copyright for this article is retained by the author(s), with first publication rights granted to the journal.

This is an open-access article distributed under the terms and conditions of the Creative Commons Attribution license (http://creativecommons.org/licenses/by/4.0/). 